\title{
Population Pharmacokinetics of Diazoxide in Children with Hyperinsulinemic Hypoglycemia
}

\author{
Rika Kizu ${ }^{a}$ e Kazuko Nishimura ${ }^{b}$ Reiko Sato $^{b}$ Kenjiro Kosaki ${ }^{c}$

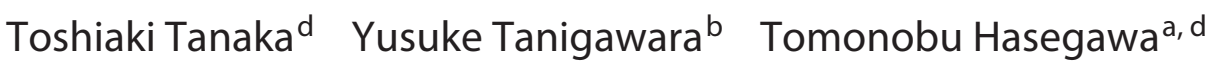 \\ ${ }^{a}$ Department of Pediatrics, Keio University School of Medicine, Tokyo, Japan; ${ }^{b}$ Department of Clinical \\ Pharmacokinetics and Pharmacodynamics, Keio University School of Medicine, Tokyo, Japan; ' Center for Medical \\ Genetics, Keio University School of Medicine, Tokyo, Japan; ' Japanese Society for Pediatric Endocrinology, Tokyo, \\ Japan; ${ }^{e}$ Department of Pediatrics,Yokosuka Kyosai Hospital, Yokosuka, Japan
}

\section{Keywords}

Diazoxide - Population pharmacokinetics .

Hyperinsulinemic hypoglycemia

\begin{abstract}
Background: Diazoxide is the first-line treatment for pediatric hyperinsulinemic hypoglycemia $(\mathrm{HI})$. This study aimed to elucidate the pharmacokinetics of diazoxide in children with HI. Methods: We obtained 81 blood samples from 22 children with $\mathrm{HI}$. Measured serum diazoxide concentrations were used for population pharmacokinetic analysis. Patient factors influencing pharmacokinetics were estimated using nonlinear mixed-effects model analysis. Relationships between drug exposure and adverse drug reactions were also investigated. Results: Diazoxide disposition in the body was described by a 1-compartment model. Oral clearance (CL/F) and the volume of distribution were proportional to body weight (WT), as expressed by $\mathrm{CL} / \mathrm{F}$ in males (liters/h) = $0.0358+0.00374 \times \mathrm{WT}(\mathrm{kg}) . \mathrm{CL} / \mathrm{F}$ in females was $39 \%$ greater than that in males. Steady-state concentrations of diazoxide were similar following twice- and 3 times-daily dosing when the total daily doses were comparable. A patient whose serum diazoxide concentration exceeded $100 \mu \mathrm{g} / \mathrm{mL}$ over a 4-month period developed hyperglycemia. No significant
\end{abstract}

correlation was observed between severity of hirsutism and diazoxide concentration. Conclusion: We have proposed for the first time a population pharmacokinetic model for diazoxide in children with $\mathrm{HI}$. The potential risk of diabetes mellitus and/or hyperglycemia increases when serum concentrations of diazoxide exceed $100 \mu \mathrm{g} / \mathrm{mL}$.

(c) 2017 The Author(s)

Published by S. Karger AG, Basel

\section{Introduction}

Hyperinsulinemic hypoglycemia (HI) [1-4], characterized by profound hypoglycemia due to inappropriate insulin secretion, is the most common cause of persistent hypoglycemia in children. Poor control of blood glucose levels in children with HI can result in neurological sequelae, including mental retardation and epilepsy.

Diazoxide raises blood glucose concentrations by suppressing insulin secretion, and this agent is the first choice for treating children with HI, although diazoxide is thought to be effective in infantile-onset HI only, and not in neonatal HI [3]. Diazoxide binds to the sulfonylurea receptor 1 subunit and inhibits closure of the ATP-sensitive potassium channel with subsequent diminished insulin secretion by pancreatic $\beta$ cells. In Japan, the starting

\section{KARGER}

E-Mail karger@karger.com www.karger.com/hrp
(C) 2017 The Author(s) Published by S. Karger AG, Basel

Karger

Open access

This article is licensed under the Creative Commons AttributionNonCommercial-NoDerivatives 4.0 International License (CC BYNC-ND) (http://www.karger.com/Services/OpenAccessLicense). Usage and distribution for commercial purposes as well as any distribution of modified material requires written permission.
Prof. Yusuke Tanigawara, $\mathrm{PhD}$

Department of Clinical Pharmacokinetics and Pharmacodynamics Keio University School of Medicine, 35 Shinanomachi, Shinjuku-ku Tokyo 160-8582 (Japan)

E-Mail tanigawara-yusuke@umin.ac.jp 
dose of diazoxide administered to children with $\mathrm{HI}$ is 5-10 $\mathrm{mg} / \mathrm{kg} / \mathrm{day}$ before the age of 1 year, and $3-5 \mathrm{mg} / \mathrm{kg} / \mathrm{day}$ thereafter [5]. This dosage regimen was determined from clinical experience worldwide, and is not based on evidence for optimal use [6].

The aim of this study was to elucidate the pharmacokinetics of diazoxide in children with $\mathrm{HI}$ by population pharmacokinetic (PPK) analysis [7-11] using nonlinear mixed-effects modeling (NONMEM) [12] methods. Up to now, the pharmacokinetics of diazoxide have been reported from only 4 adults $[13,14]$ and 4 children [14], yielding insufficient information considering this agent is used as a first-line treatment for $\mathrm{HI}$ in children. PPK analysis is recommended by the FDA in the US and the Pharmaceuticals and Medical Devices Agency (PMDA) in Japan as a useful method for assessing special populations such as pediatric and geriatric patients, and patients with complicated organ diseases $[15,16]$, as it can analyze pharmacokinetic features using sparsely sampled data which is more feasible in clinical settings [12].

We also investigated relationships between drug exposure and responses, including adverse reactions and pharmacological surrogates. The most common adverse events related to diazoxide include edema and hirsutism [6], with the latter occurring prominently in children, sometimes leading to discontinuation of the drug.

\section{Subjects and Methods}

\section{Patients}

Children newly or already diagnosed with $\mathrm{HI}$ and being treated with diazoxide (Proglycem; Schering-Plough, NJ, USA) were recruited prospectively from a multicenter study group for this investigation from July 2004 to July 2007 in Japan. Compliance was determined by questionnaire to the parent(s) or attending doctors. The exclusion criteria of this study were poor compliance, forgetting to take diazoxide on the day before blood sampling, patients older than 20 years of age, and co-treatment with corticosteroids or growth hormone.

The present study was approved by the Ethics Committee, Keio University Hospital, and written informed consent was obtained from the parent(s) of all enrolled patients.

\section{Treatment}

The physicians-in-charge determined the dosage regimen for each patient. When the patients received diazoxide at the same dose for longer than 1 week, serum diazoxide concentrations were considered to be at steady state, based on the reported half-life of diazoxide of $28 \pm 8.3 \mathrm{~h}$ in adults [17] and steady state being theoretically reached after 5 times the half-life [18].

\section{Blood Sampling}

Blood samples were obtained for the measurement of serum diazoxide concentrations and for routine laboratory testing (e.g., total cell counts and blood chemistry). For the PPK analysis, parent(s) or physicians recorded the exact times of administration of diazoxide or blood sampling, respectively.

\section{Serum Diazoxide Assay}

Serum diazoxide concentrations were measured according to a previously reported method, with minor modifications [19-21]. Diazoxide and phenacetin, used as an internal standard, were purchased from Sigma Chemical Co. (St. Louis, MO, USA) and Wako Pure Chemical Industries, Ltd. (Osaka, Japan), respectively. Quantitation of diazoxide was carried out using high-performance liquid chromatography (HPLC) with ultraviolet detection. After separation of the serum by centrifugation, the samples were stored at $-20^{\circ} \mathrm{C}$.

For the diazoxide assay, serum aliquots of $100 \mu \mathrm{L}$ were mixed with $50 \mu \mathrm{L}$ of $200 \mu \mathrm{g} / \mathrm{mL}$ phenacetin. Proteins were precipitated by adding $400 \mu \mathrm{L}$ of $0.33 \mathrm{M}$ perchloric acid solution and $50 \mu \mathrm{L}$ of $50 \%$ methanol $(\mathrm{MeOH})$. Samples were then vortexed (20 s) and centrifuged $\left(12,000 \mathrm{rpm}, 20 \mathrm{~min}, 5^{\circ} \mathrm{C}\right)$, and $20 \mu \mathrm{L}$ of the supernatant was injected onto the HPLC system.

Chromatographic separation was carried out at a flow rate of $1 \mathrm{~mL} / \mathrm{min}$ with a binary mobile phase consisting of $0.01 \mathrm{M} 1$-pentanesulfonic acid sodium salt solution with $0.1 \%$ (v/v) acetic acid and $\mathrm{MeOH}$. The following step gradient profile was used for HPLC: $40 \% \mathrm{MeOH}$ for $7.5 \mathrm{~min}$, increasing up to $95 \% \mathrm{MeOH}$ over $2.5 \mathrm{~min}$, isocratic at $95 \% \mathrm{MeOH}$ for $7 \mathrm{~min}$, decreasing to $40 \%$ $\mathrm{MeOH}$ within $0.01 \mathrm{~min}$, and remaining constant until the end of the run. Diazoxide and the internal standard were separated using an Inertsil ODS-3 column $(5 \mu \mathrm{m}, 4.6 \times 150 \mathrm{~mm}$; GL Sciences, Tokyo, Japan), maintained at $40^{\circ} \mathrm{C}$ and then detected, respectively, at $270 \mathrm{~nm}$. The retention times of diazoxide and the internal standard were 6.0 and $9.0 \mathrm{~min}$, simultaneously. Standard curves for serum diazoxide concentration were linear within the range from 0.5 to $200 \mu \mathrm{g} / \mathrm{mL}$, with the lower limit of detection being $0.5 \mu \mathrm{g} /$ $\mathrm{mL}$. The inter- and intraday variability in accuracy (expressed as relative error) for the diazoxide assay was $2.0 \%(0.51 \mu \mathrm{g} / \mathrm{mL})$ and $-0.6 \%(202.3 \mu \mathrm{g} / \mathrm{mL})$, and $2.0 \%(0.51 \mu \mathrm{g} / \mathrm{mL})$ and $0.4 \%(202.3 \mu \mathrm{g} /$ $\mathrm{mL})$, respectively. The inter- and intraday variability in precision (expressed as the coefficient of variation) was $1.9 \%(0.51 \mu \mathrm{g} / \mathrm{mL})$ and $0.7 \%(202.3 \mu \mathrm{g} / \mathrm{mL})$, and $1.9 \%(0.51 \mu \mathrm{g} / \mathrm{mL})$ and $0.7 \%(202.3$ $\mu \mathrm{g} / \mathrm{mL})$, respectively. The recovery of added diazoxide standards to serum was $78.3 \pm 3.3 \%(0.5 \mu \mathrm{g} / \mathrm{mL})$ and $80.4 \pm 0.9 \%(200 \mu \mathrm{g} /$ $\mathrm{mL})$.

\section{PPK Analysis of Diazoxide}

Pharmacokinetic Model

PPK analysis was performed using NONMEM 7.3.0 software with a PREDPP library [12]. The pharmacokinetics of diazoxide were assumed to adhere to a 1-compartment model with first-order elimination from the central compartment [14]. The structural parameters were total body clearance $(\mathrm{CL} / \mathrm{F}$, in which $\mathrm{F}$ represents oral bioavailability) and volume of distribution in the central compartment $(\mathrm{V} / \mathrm{F}) . \mathrm{CL} / \mathrm{F}$ and $\mathrm{V} / \mathrm{F}$ were estimated using a model from the PREDPP library (ADVAN2, TRANS2), represented as follows:

$$
\begin{aligned}
& \mathrm{C}=\mathrm{F} \times \mathrm{D} \times k a / \mathrm{V} \times(k a-k e) \times\{\exp (-k e \times \mathrm{t})-\exp (-k a \times \mathrm{t})\}, \\
& \mathrm{CL}=\mathrm{V} \times k e,
\end{aligned}
$$

where $\mathrm{C}$ denotes the concentration of the drug in the serum, D represents dose (mg), $k a$ is the first-order absorption rate constant, 
$k e$ is the first-order elimination rate constant derived as CL/V, and $\mathrm{t}$ is time after dose (h).

The interindividual variability in $\mathrm{CL} / \mathrm{F}$ and in $\mathrm{V} / \mathrm{F}$ was assumed to obey a log-normal distribution, expressed by the following equations:

$$
\begin{aligned}
& \ln \mathrm{CL} i=\ln \mathrm{CL}+\eta^{\mathrm{CL}} i, \\
& \ln \mathrm{V} i=\ln \mathrm{V}+\eta^{\mathrm{V}} i,
\end{aligned}
$$

where $\eta i$ denotes the difference between the individual parameters $(\mathrm{CL} i, \mathrm{~V} i$ ) for subject $i$ and the typical values of CL and $\mathrm{V}$ predicted by the population mean. The $\eta$ is distributed with a mean of zero and a variance equal to $\omega^{2}$. The addition of $\omega$ on $k a$ resulted in model instability, and thus, $\omega$ for $k a$ was not included in our population model.

The residual variability of concentrations includes drug assay error, intraindividual variability, and deviations caused by model misspecification, and is described by the log-normal distribution model:

$$
\ln C_{i, j}=\ln _{i, j}+\varepsilon_{i, j},
$$

where $\mathrm{C}_{\mathrm{i}, \mathrm{j}}$ and $\mathrm{i}_{\mathrm{i}, \mathrm{j}}$ are the observed and predicted diazoxide concentrations, respectively, at time $t_{i}$ for a subject $j . \varepsilon_{\mathrm{i}, j}$ represents independent, identically distributed random errors with mean zero and variance $\sigma^{2}$ for serum concentrations.

Factors Affecting the Pharmacokinetics of Diazoxide

Covariates that could influence the pharmacokinetics of diazoxide were added one by one in a stepwise fashion to the basic model without any covariates. The individual post hoc estimates of diazoxide CL/F were obtained from the basic model before adding a covariate, and a linear relationship between diazoxide CL/F and body weight (WT) (kg) was observed. In the same way, a linear relationship was also observed between diazoxide V/F and WT. Age was a confounding variable which correlated to WT. As the dose of diazoxide was determined conventionally based on WT, we incorporated this as a fixed-effect variable into the basic model. For each model, the improvement in fit obtained on adding a fixed-effect variable into the base model was assessed by the difference in objective function, which is equivalent to -2 (log-likelihood difference). This difference in the value of the objective function ( -2 log-likelihood difference) is asymptotically distributed as $\chi^{2}$ with degrees of freedom equal to the number of added/reduced parameters. A change in the objective function value of 3.841 with the degrees of freedom equal to 1 indicated statistical significance $(p<0.05)$. We examined several potential covariates (age, gender, concomitant use of antiepileptic drugs, and severity of $\mathrm{HI}$ ) which could affect CL/F or V/F. Thereafter, a final population model was obtained by including all significant covariates, and the final PPK parameters were estimated.

\section{Model Validation}

The PPK parameters and the final model obtained in the above analysis were qualified by the following methods.

Diagnostic analyses compared the observed serum diazoxide concentrations and the individually predicted concentrations using Bayesian estimation. The stability and robustness of the final model were assessed by a bootstrap validation $[22,23]$, which involved taking 200 datasets constructed by resampling from the original dataset, and fitting the final model repeatedly to these datasets to obtain the PPK parameters. The median and 5th and 95th percentiles of 200 parameter estimates obtained from successful bootstrap replicates were compared to the final parameter estimates from the original dataset.

Effect of Divided Doses per Day

The Bayesian method was employed to estimate individual pharmacokinetic parameters using measured serum diazoxide concentrations and the final PPK parameters. The elimination half-life $\left(\mathrm{T}_{1 / 2}\right)$ and the predicted average serum concentration at steady state $\left(\mathrm{C}_{\mathrm{ss}, \mathrm{av}}\right)$ were calculated by the following equations:

$$
\begin{aligned}
& \mathrm{T}_{1 / 2}=0.693 \mathrm{~V} / \mathrm{CL}, \\
& \mathrm{C}_{\mathrm{ss}, \mathrm{av}}=\mathrm{F} \times \mathrm{D} /(\mathrm{CL} \times \tau),
\end{aligned}
$$

where $\tau$ represents the dosing interval $(h)$.

To investigate the effect of divided doses per day, we compared the simulated $\mathrm{C}_{\mathrm{ss} \text {,av }}$ values between patients treated twice a day with oral diazoxide (twice-daily group) and those treated 3 times a day (3 times-daily group). For this simulation, we assumed 12 and $8 \mathrm{~h}$, respectively, as dosing intervals. Furthermore, entire serum diazoxide concentration time profiles were simulated for a typical patient (male, $20 \mathrm{~kg} \mathrm{WT}$ ) treated with $7.5 \mathrm{mg} / \mathrm{kg} /$ day diazoxide orally at different time intervals during the day.

\section{Exposure and Response (Efficacy and Adverse Drug Reactions)} Analysis

Each physician-in-charge evaluated the following 4 items subjectively and categorized them into 3-5 groups: (1) efficacy of diazoxide in blood glucose control ( 5 groups; very effective, effective, slightly effective, ineffective, and the data could not be obtained), (2) the severity of HI as evaluated based on the hypoglycemic condition (3 groups; mild, moderate, severe), (3) edema (3 groups: none, transient, permanent), and (4) hirsutism (4 groups: none, mild, moderate, and severe), according to the physician's global assessment. Hirsutism was evaluated in selected patients who were treated with the same dose of diazoxide for more than 1 month.

\section{Statistical Analysis}

Statcel ${ }^{\mathrm{TM}}$ version 2 was used for statistical analysis. The nonparametric Mann-Whitney U test was used to compare differences in $\mathrm{C}_{\mathrm{ss}, \mathrm{av}}$ between the twice- and 3 times-daily groups, and the Kruskal-Wallis test was used to compare differences in $\mathrm{C}_{\mathrm{ss}, \mathrm{av}}$ among 4 groups, scaled for hirsutism. A $p$ value of less than 0.05 was considered statistically significant.

\section{Results}

\section{Patients and Data}

Of the 23 pediatric patients enrolled in this study, 1 patient was diagnosed as having Turner syndrome and received growth hormone therapy. We excluded this subject as growth hormone therapy influences blood glucose levels, and this could have affected the evaluation of diazoxide efficacy. Therefore, we performed population pharmacokinetic and pharmacodynamic analysis of diazoxide using serum concentration data from 81 samples taken from 22 patients. Table 1 summarizes the charac- 
Table 1. Characteristics of the patients who participated in the present study

\begin{tabular}{|c|c|c|c|}
\hline & Number & Median & Range $^{a}$ \\
\hline Patients & 22 & & \\
\hline Serum samples & 81 & & \\
\hline Serum samples/patient & & 3 & $1-13$ \\
\hline Gender (male/female) & $17 / 5$ & & \\
\hline Age, years & & 4.3 & $0.1-15.2$ \\
\hline Weight, kg & & 17.5 & $3.5-70.6$ \\
\hline Serum creatinine, $\mathrm{mg} / \mathrm{dL}$ & & 0.3 & $0.1-0.47$ \\
\hline Daily diazoxide dose, $\mathrm{mg} / \mathrm{kg} /$ day & & 6.7 & $2.3-15.1$ \\
\hline $\begin{array}{l}\text { Divided doses per day } \\
\text { (once/ twice } / 3 \text { times/4 times) }\end{array}$ & $1 / 10 / 10 / 1$ & & \\
\hline Severity (mild/moderate/severe) ${ }^{\mathrm{b}}$ & $3 / 10 / 9$ & & \\
\hline Concomitant antiepileptic drugs (yes/no) & $5 / 17$ & & \\
\hline Treatment period with diazoxide, years & & $\begin{array}{l}3.5(1 \text { st time - } \\
11.25)\end{array}$ & \\
\hline
\end{tabular}

${ }^{\mathrm{a}}$ Minimum-maximum values. ${ }^{\mathrm{b}}$ Severity classification for male patients: 1 mild, 8 moderate, and 8 severe disease.

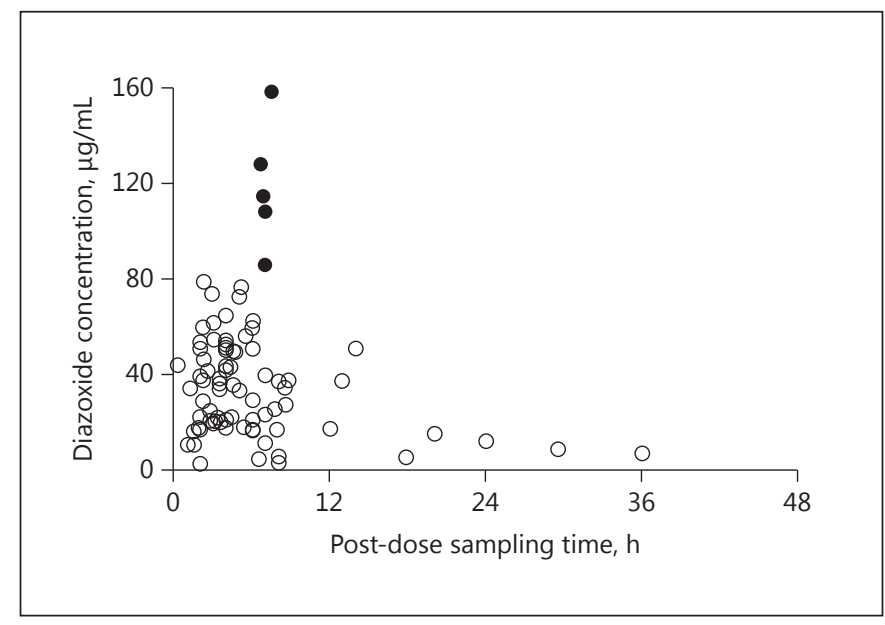

Fig. 1. Diazoxide concentrations in serum vs. post-dose sampling time. The closed circles represent the observed values in patient 13 who developed hyperglycemia, and the open circles represent all other patients.

teristics of the 22 patients. Four patients were newly diagnosed with $\mathrm{HI}$, and 18 patients had been diagnosed previously. Five patients received concomitant treatment with anticonvulsants such as carbamazepine, clobazam, valproic acid, phenobarbital, or zonisamide. Two patients were diagnosed with glutamate dehydrogenase deficiency. Figure 1 shows the serum concentrations of diazoxide versus post-dose sampling times.

\section{PPK of Diazoxide}

Diazoxide disposition in the body was described by a 1-compartment model. Both $\mathrm{CL} / \mathrm{F}$ and $\mathrm{V} / \mathrm{F}$ were described proportional to WT. Table 2 details the univariate hypothesis testing for each factor that could have affected the pharmacokinetics of diazoxide. Gender and the severity of $\mathrm{HI}$ had a significant influence on CL/F, while neither concomitant antiepileptic drug administration nor age significantly influenced $\mathrm{CL} / \mathrm{F}$ or $\mathrm{V} / \mathrm{F}$. In a subsequent multivariate analysis, gender difference was incorporated into the PPK model.

The final estimates for the PPK parameters of diazoxide are summarized in Table 3. CL/F in females was 1.4 times greater than that in males. The estimated interindividual variability in $\mathrm{CL} / \mathrm{F}$ and $\mathrm{V} / \mathrm{F}$ was 37.3 and $49.3 \%$, respectively, and the intraindividual residual variability for diazoxide concentration was $20.1 \%$.

The obtained pharmacokinetic model and its parameters were qualified by diagnostic analyses and a bootstrap validation. Comparison of the observed versus predicted values revealed no systematic bias in the prediction of plasma concentrations (online suppl. Fig. 1a; see www. karger.com/doi/10.1159/000478696 for all online suppl. material), while the weighted residuals were uniformly scattered around the horizontal axis of zero (online suppl. Fig. 1b). The final model was then fitted repeatedly to 200 bootstrap-resampled datasets, and all 200 were successfully converged. The medians of the parameter estimates obtained from the bootstrap analyses were comparable to the final parameter estimates obtained from the original 
Table 2. Hypothesis testing for factors affecting pharmacokinetics of diazoxide

\begin{tabular}{llrl}
\hline Factor & OBJ & $\Delta$ OBJ & $p$ value $^{\mathrm{a}}$ \\
\hline Basic model & 450.165 & & \\
Gender on CL/F & 444.472 & 5.693 & $<0.025$ \\
Concomitant antiepileptic drugs on CL/F & 449.367 & 0.798 & $\mathrm{~ns}$ \\
Age on CL/F & 449.642 & 0.523 & $\mathrm{~ns}$ \\
Severity of HI on CL/F & 433.035 & 17.130 & $<0.005$ \\
Gender on V/F & 449.885 & 0.280 & $\mathrm{~ns}$ \\
Concomitant antiepileptic drugs on V/F & 449.571 & 0.594 & $\mathrm{~ns}$ \\
Age on V/F & 449.570 & 0.595 & $\mathrm{~ns}$ \\
Severity of HI on V/F & 449.951 & 0.214 & $\mathrm{~ns}$ \\
\hline
\end{tabular}

OBJ, objective function values. HI, hyperinsulinemic hypoglycemia; CL/F, total body clearance (in which F represents oral bioavailability); V/F, volume of distribution in the central compartment; ns, not statistically significant. ${ }^{a}$ Significance criterion: $\triangle \mathrm{OBJ}(-2$ log-likelihood difference) $>3.841, p<0.05$. dataset (online suppl. Table 1). Some parameters $(\theta 2, \theta 4$, $\theta 5, \omega)$ showed large confidence intervals due to the small number of subjects.

\section{Effect of Divided Doses per Day}

Individual pharmacokinetic parameters were estimated using the PPK parameters and observed diazoxide concentrations for each patient by the Bayesian algorithm. The $\mathrm{T}_{1 / 2}$ of diazoxide was estimated to be $15 \pm$ $5.3 \mathrm{~h}$ (range: 5.9-27.7). The predicted average serum concentration at steady state $\left(\mathrm{C}_{\mathrm{ss}, \mathrm{av}}\right)$ of diazoxide correlates with diazoxide dose/kg/day (online suppl. Fig. 2).

There was no significant difference in $\mathrm{C}_{\mathrm{ss} \text {,av }}$ between the twice- and 3 times-daily groups (Fig. 2b). These 2 groups were not significantly different in terms of the male/female ratio, concomitant antiepileptic drug use, and daily diazoxide dose $(6.0 \pm 2.3 \mathrm{mg} / \mathrm{kg} /$ day in the twice-daily group and $7.8 \pm 4.0$ in the 3 times-daily group), while there was a significant difference in age: $8.0 \pm 4.1$ years in the twice-daily group and $2.3 \pm 2.3$ years in the 3 times-daily group.

Time courses of serum diazoxide concentration resulting from different dosing regimens, with specific dosing intervals per day, were simulated over 96 h (Fig. 2a). Once-daily dosing resulted in a large difference compared to the other regimens; however, virtually no difference was seen between the twice- and 3 times-daily regimens. Therefore, the pharmacokinetic simulations revealed that the steady-state concentrations of diazoxide are similar with respect to twice- and 3 times-daily dosing as long as the total daily doses are comparable.

Pharmacokinetics of Diazoxide in Children
Table 3. Population pharmacokinetic model and parameter estimates of diazoxide in children with hyperinsulinemic hypoglycemia

\begin{tabular}{ll}
\hline Clearance $(\mathrm{CL} / \mathrm{F}), \mathrm{L} / \mathrm{h}$ & \\
$\quad$ Male & $0.0358+0.00374 \times \mathrm{WT}$ \\
$\quad$ Female & $0.0498+0.00520 \times \mathrm{WT}$ \\
Distribution volume $(\mathrm{V} / \mathrm{F}), \mathrm{L}$ & $1.37+0.0459 \times \mathrm{WT}$ \\
Absorption rate constant $(\mathrm{Ka}), 1 / \mathrm{h}$ & 0.596 \\
Interindividual variability & \\
$\omega_{\mathrm{CL}}^{2}$ & $0.139(37.3 \% \mathrm{CV})$ \\
$\omega_{\mathrm{v}}^{2}$ & $0.243(49.3 \% \mathrm{CV})$ \\
Intraindividual variability $\left(\delta^{2}\right)$ & $0.0406(20.1 \% \mathrm{CV})$
\end{tabular}

$\mathrm{CL}$ ratio of female $/$ male $=1.39 . \mathrm{CL} / \mathrm{F}$, total body clearance (in which F represents oral bioavailability); V/F, volume of distribution in the central compartment; WT, body weight (kg); CV, coefficient of variation.

\section{Pharmacokinetics/Pharmacodynamics of Diazoxide}

Diazoxide was considered very effective in controlling blood glucose levels in 7 patients; it was effective in 14 patients, and its efficacy could not be evaluated in $1 \mathrm{pa}-$ tient.

The $\mathrm{C}_{\text {ss,av }}$ of 1 patient who suffered permanent edema and who did not receive diuretic treatment was $70.2 \mu \mathrm{g} /$ $\mathrm{mL}$, while that of the other 3 patients who had recovered from edema, 2 of whom were administered diuretics, ranged from 42.3 to $120.7 \mu \mathrm{g} / \mathrm{mL}$. Diazoxide was not discontinued in any of these 4 patients. We were not able to analyze the correlation between $\mathrm{C}_{\mathrm{ss}, \mathrm{av}}$ and edema statistically, as the edema was permanent in only 1 patient, and transient in the other 3 patients. There was no significant 


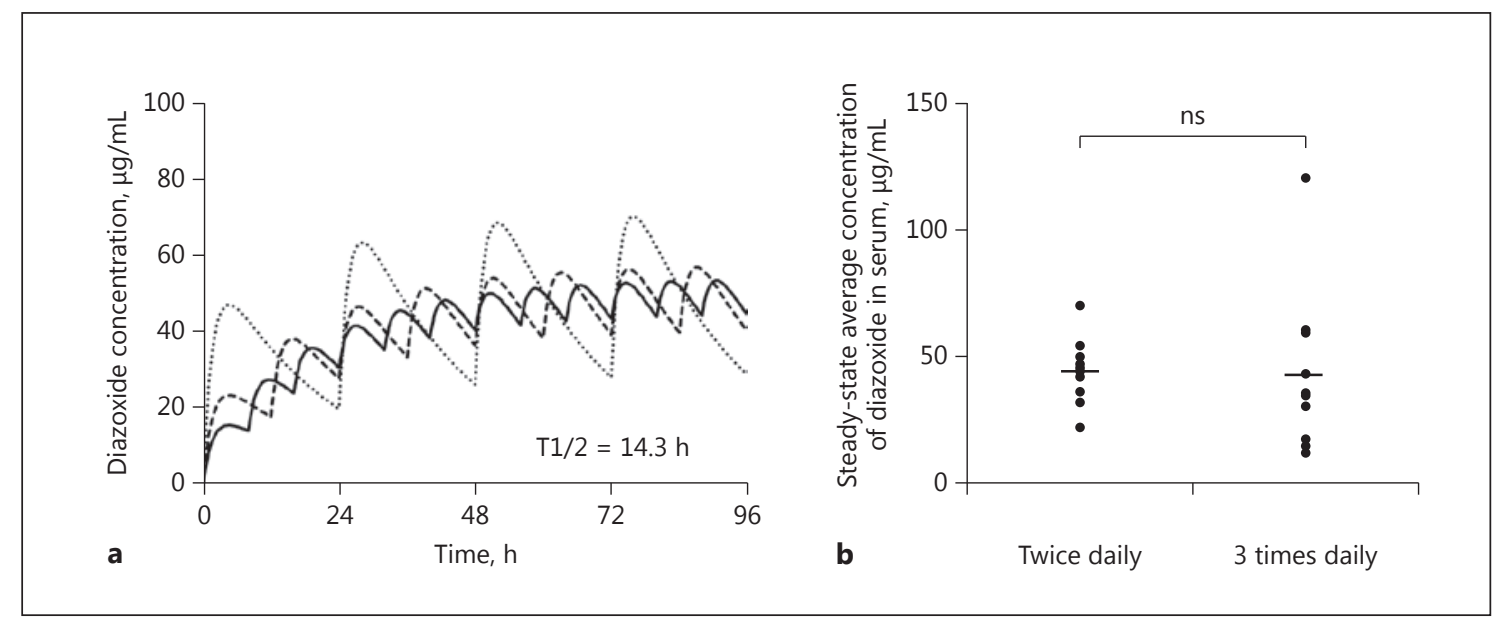

Fig. 2. Simulated serum concentration profiles of diazoxide in children according to the obtained population pharmacokinetic parameters. a Simulated serum concentration profiles of diazoxide (from the first dose to $96 \mathrm{~h}$ ) in a typical male patient treated with oral diazoxide at a dose of $7.5 \mathrm{mg} / \mathrm{kg} /$ day with differently divided doses per day. The solid, broken, and dotted lines represent
3 times-, twice-, and once-daily administration, respectively. b Steady-state average concentration of diazoxide in serum $\left(\mathrm{C}_{\mathrm{ss}, \mathrm{av}}\right)$ for 20 subjects. The $\mathrm{C}_{\mathrm{ss}, \mathrm{av}}$ was $44.6 \pm 13.0 \mu \mathrm{g} / \mathrm{mL}$ for the twicedaily dosing group $(n=10)$ and $43.1 \pm 32.1 \mu \mathrm{g} / \mathrm{mL}$ for the 3 times-daily dosing group $(n=10)$. There was no statistically significant difference between the 2 groups.

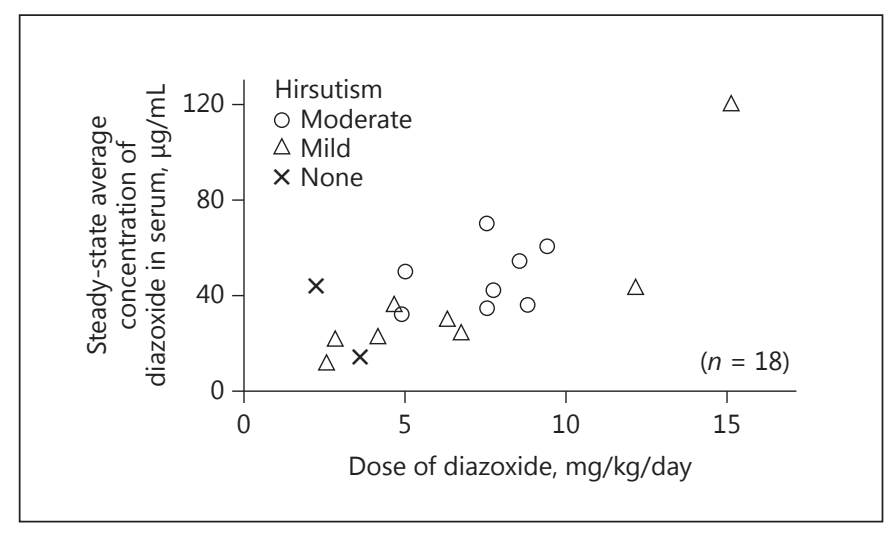

Fig. 3. Relationship between the steady-state average concentration of diazoxide in serum and diazoxide dose vs. severity of hirsutism. Hirsutism could be evaluated in 18 patients. The open circles, triangles, and crosses represent moderate, mild, and no hirsutism, respectively.

correlation between the estimated $\mathrm{C}_{\mathrm{ss}, \mathrm{av}}$ and severity of hirsutism (shown in Fig. 3), while online supplementary Figure 3 shows no influence of the treatment period.

It is of note that 1 patient developed hyperglycemia. This patient was administered excessively high doses of diazoxide for a long period, in order to prevent hypoglycemia on days he was sick due to a short fasting duration and repeated moderate early morning hypoglycemia at the age
Table 4. Laboratory data of a patient who developed hyperglycemia (patient 13)

\begin{tabular}{lllll}
\hline & $\begin{array}{l}\text { Diazoxide, } \\
\mathrm{mg} / \mathrm{kg} / \mathrm{day}\end{array}$ & $\begin{array}{l}\text { Serum } \\
\text { concentration } \\
\text { of diazoxide, } \\
\mu \mathrm{g} / \mathrm{mL}\end{array}$ & $\begin{array}{l}\text { Blood } \\
\text { glucose, } \\
\mathrm{mg} / \mathrm{dL}\end{array}$ & $\begin{array}{l}\mathrm{HbA}_{\mathrm{lc}} \\
(\mathrm{NGSP}), \\
\%\end{array}$ \\
\hline At the first & & & & \\
measurement & 14 & 86.3 & 123 & 5.8 \\
At 1 month & 14 & 108.7 & 100 & 6.1 \\
At 2 months & 14 & 114.9 & 103 & 5.6 \\
At 3 months & 14 & 128.5 & 104 & 6.6 \\
At 4 months & 18 & 158.4 & 212 & 6.8 \\
\hline
\end{tabular}

NGSP, National Glycohemoglobin Standardization Program.

of 2.5 years. The diazoxide concentration was $128.5 \mu \mathrm{g} / \mathrm{mL}$ at a dose of $14 \mathrm{mg} / \mathrm{kg} / \mathrm{day}$, while the nonfasting blood glucose level was $104 \mathrm{mg} / \mathrm{dL}$, and $\mathrm{HbA}_{1 \mathrm{c}}$ was measured as 6.6\% (National Glycohemoglobin Standardization Program, NGSP) (Table 4). The concentration of diazoxide was further elevated to $158.4 \mu \mathrm{g} / \mathrm{mL}$ at a dose of $18 \mathrm{mg} / \mathrm{kg} /$ day, and this patient was diagnosed with diabetes mellitus based on a blood glucose level of $212 \mathrm{mg} / \mathrm{dL}$ and an $\mathrm{HbA}_{1 \mathrm{c}}$ measurement of $6.8 \%$. The level of $\mathrm{HbA}_{1 \mathrm{c}}$ returned to normal when the diazoxide dose was reduced to $14 \mathrm{mg} / \mathrm{kg} /$ day. No fatal adverse event was reported in this study. 


\section{Discussion}

In this study, we elucidated the pharmacokinetics of diazoxide in children with $\mathrm{HI}$ for the first time using PPK analysis, resulting in novel findings regarding pharmacokinetic parameters, covariates, model structure, the halflife of diazoxide, and the effects of divided doses per day.

We found that WT had a significant influence on CL/F and $\mathrm{V} / \mathrm{F}$, although age had no influence. However, it is to be expected that age had no further effect on the pharmacokinetics of diazoxide, as WT is usually proportional to age during childhood, and we confirmed this proportional relationship among the patients who participated in this study.

Gender difference and the severity of $\mathrm{HI}$ were found to be potential covariates with respect to $\mathrm{CL} / \mathrm{F}$ (Table 2). The pharmacokinetics of diazoxide have been investigated previously in males, but females have not been studied, and gender difference has never been reported. The present patient population included 5 females, and we found a gender difference in CL/F, with females showing a 39\% greater $\mathrm{CL} / \mathrm{F}$ than males. However, due to the lack of balance in the number of male and female patients here, further study is needed to confirm gender difference. In a subsequent multivariate analysis, gender and the severity of HI were correlated, because when gender difference was incorporated as a covariate on $\mathrm{CL} / \mathrm{F}$, the severity effect disappeared, and vice versa. As the physicians' evaluation of severity was subjective and no predetermined criteria existed, we did not accept the severity information as a final result of this analysis. Further studies are needed to investigate the potential contribution of gender difference and/or the severity of HI.

Concomitant use of antiepileptic drugs had no significant influence on CL/F and V/F. We attributed this result to the different disposition pathways utilized by antiepileptic drugs and diazoxide. Typically, antiepileptic drugs are metabolized by CYP450 in the liver, while diazoxide is excreted by the kidneys. Pruitt et al. [14] reported that the half-life of diazoxide was shorter in 2 children receiving phenobarbital and diphenylhydantoin, and attributed this to concomitant use of an antiepileptic agent. However, we suspect that confounding factor(s), such as WT, affected the outcome of this study.

Model validation also indicated the stability of the final model and the reliability of the parameter estimates (online suppl. Fig. 1 and Table 1). However, we should keep in mind other potential factors that could bring about inter- and intraindividual pharmacokinetic variability associated with diazoxide. There are unknown possibly in-

Pharmacokinetics of Diazoxide in Children fluential covariates such as the pathogenic mechanisms related to $\mathrm{HI}$ and creatinine clearance. As $\mathrm{HI}$ is a clinically and genetically heterogeneous disorder [1-6, 24], and diazoxide is excreted by the kidneys [13], renal function can be an important covariate candidate, although serum creatinine levels were normal in all of the patients who participated in this study.

The obtained half-life of diazoxide varied from 5.9 to $27.7 \mathrm{~h}$, which is consistent with previous reports citing 9.5-24 h [14]. Our simulations indicated no significant difference in the $\mathrm{C}_{\mathrm{ss}, \text { av }}$ between the twice- and 3 timesdaily dosing groups. The pharmacokinetic simulations also showed a similarity in the fluctuation of the diazoxide concentration between the twice a day and 3 times a day dosage regimens. In contrast, the fluctuation seen when the drug was given once daily was extremely large. Thus, divided dosing at twice per day is equally acceptable to dosing 3 times a day.

Two adverse events were notable in the patients studied here, hirsutism and diabetes mellitus. Hirsutism is one of the most common adverse events reported during diazoxide therapy, and it was apparent in this study in 16 out of 18 analyzed cases. We did not find a significant correlation between the severity of hirsutism and the concentration of diazoxide, suggesting that this adverse event could be independent of drug concentration. One patient (patient 13) developed diabetes mellitus, which we attribute to diazoxide based on its pharmacological effects, the long-term high exposure to diazoxide $(>100 \mu \mathrm{g} / \mathrm{mL})$, and particularly, as his measured $\mathrm{HbA}_{1 \mathrm{c}}$ of $6.8 \%$ was associated with a serum concentration of diazoxide of $158.4 \mu \mathrm{g} /$ $\mathrm{mL}$, which was far higher than that observed in the other patients. Pruitt et al. [14] reported on a boy who experienced hyperglycemia after receiving diazoxide at $30 \mathrm{mg} /$ $\mathrm{kg} /$ day for 4 days, and the concentration of diazoxide measured in the patient's serum was $120 \mu \mathrm{g} / \mathrm{mL}$. We speculate that a risk of diabetes mellitus and/or hyperglycemia may be increased when the serum concentration of diazoxide exceeds $100 \mu \mathrm{g} / \mathrm{mL}$.

The limitations of this study are the small number of patients, the unbalanced number of male and female patients, the lack of predetermined criteria regarding the severity of HI, and the possibility that our study population included some subjects with transient-type HI who had already been in spontaneous remission, leading to overestimation of the efficacy of diazoxide. Diazoxide was evaluated to be effective in all cases except for 1 patient. Measurement of 1,5-AG (1,5-anhydro-D-glucitol) before and after changing the diazoxide dose may provide additional efficacy information in future studies, as 1,5- 
AG reflects average blood glucose levels for a shorter period than $\mathrm{HbA}_{1 \mathrm{c}}$.

In conclusion, we have proposed the first PPK model for diazoxide in children with HI. Steady-state concentrations of diazoxide were similar between twice- and 3 times-daily dosing as long as the total daily doses were comparable. It seems logical to use empirically determined doses and divided doses per day. However, the potential risk of diabetes mellitus and/or hyperglycemia increases when the serum concentration of diazoxide exceeds $100 \mu \mathrm{g} / \mathrm{mL}$.

\section{Acknowledgments}

We thank all patients and their parents for participating in this study. We are indebted to the following attending physicians for enrolling patients in the study: T. Uragami (Surugadai Nihon University Hospital), T. Esaki (Ashikaga Red Cross Hospital), H. Igarashi (Igarashi Pediatric Clinic), K. Kosaka (Kyoto Prefectural University of Medicine), T. Oura (Tohoku University Hospital),
M. Miyawaki (Kozagawa National Health Insurance Hospital), Y. Shoji (Akita University Faculty of Medicine), E. Tokuhiro (Odawara City Hospital), M. Kaji and A. Uematsu (Shizuoka Children's Hospital), A. Kamei (Iwate Medical University), S. Takakuwa (University of The Ryukyus Hospital), T. Tajima (Hokkaido University School of Medicine), T. Momoi (Japanese Red Cross Society, Wakayama Medical Center), T. Yorifuji (Kyoto University Hospital), S. Yamaguchi (Shimane University Faculty of Medicine), T. Tsuchiya (Dokkyo Medical University Koshigaya Hospital), R. Yoshida (Saitama Social Insurance Hospital), M. Goto (Tokyo Metropolitan Hachioji Children's Hospital), Y. Okano (Department of Human Development and Welfare Graduate School of Human Life Science), K. Muroya (Kanagawa Children's Medical Center), Y. Naiki (National Center for Child Health and Development), S. Ida (Osaka Medical Center and Research Institute for Maternal and Child Health), S. Inoue (National Miyazakihigashi Hospital) and I. Kamimaki (National Hospital Organization Saitama National Hospital).

\section{Disclosure Statement}

The authors have no conflicts of interest to declare.

\section{References}

1 Sperling MA: Hypoglycemia; in Kliegman RM, Stanton BMD, St. Geme J, Schor NF, Behrman RE (eds): Nelson Textbook of Pediatrics, ed 19. Philadelphia, Saunders, 2011, pp 517-531.

2 Cryer PE: Hypoglycemia in infancy and childhood; in Kronenberg HM, Melmed S, Polonsky KS, Larsen PR (eds): Williams Textbook of Endocrinology, ed 12. Philadelphia, Saunders, 2011, pp 1570-1573.

-3 Dekelbab BH, Sperling MA: Recent advances in hyperinsulinemic hypoglycemia of infancy. Acta Paediatr 2006;95:1157-1564.

-4 Kapoor RR, Flanagan SE, James C, Shield J, Ellard S, Hussain K: Hyperinsulinemic hypoglycemia. Arch Dis Child 2009;94:450-457.

5 Tomonobu H, Toshiaki T, Kanzaki S, et al: Diagnosis and treatment guideline for hyperinsulinemic hypoglycemia in children. J Jpn Pediatr Soc 2006;110:1472-1474.

6 UpToDate: Treatment and complications of persistent hyperinsulinemic hypoglycemia of infancy. http://www.uptodate.com/contents/ treatment-and-complications-of-persistenthyperinsulinemic-hypoglycemia-of-infancy (accessed January 17, 2012).

7 Hori R, Okumura K, Yasuhara M, Tanigawara Y: Population pharmacokinetics and the Bayesian method for individualization of drug dosage regimens. Advances in Therapeutic Drug Monitoring Proceedings of the 1st International Congress of Therapeutic Drug Monitoring 1990, pp 109-113.
8 Minto C, Schnider T: Expanding clinical applications of population pharmacodynamic modeling. Rr J Clin Pharmacol 1998;46:321-333.

-9 Sun H, Fadiran E, Jones C, et al: Population pharmacokinetics. A regulatory perspective. Clin Pharmacokinet 1999;37:41-58.

10 Samara E, Granneman R: Role of population pharmacokinetics in drug development: a pharmaceutical industry perspective. Clin Pharmacokinet 1997;32:294-312.

11 Ludden T: Population pharmacokinetics. J Clin Pharmacol 1988;28:1059-1063.

12 Beal SL, Sheiner LB, Boekmann AJ (eds): 1989-2006 NONMEM Users Guides. Ellicott City, GloboMax, 2006.

13 Pruitt AW, Faraj BA, Dayton PG: Metabolism of diazoxide in man and experimental animals. J Pharmacol Exp Ther 1974;188:248-256.

14 Pruitt AW, Dayton PG, Patteson JH: Disposition of diazoxide in children. Clin Pharmacol Ther 1973;14:73-82.

15 Guidance for Industry: Population Pharmacokinetics. US Department of Health and $\mathrm{Hu}$ man Services, Food and Drug Administration, Center for Drug Evaluation and Research (CDER), Center for Biologics Evaluation Research (CBER), 1999.

16 Guidance for Industry: General Considerations for Pediatric Pharmacokinetic Studies for Drugs and Biological Products. US Department of Health and Human Services, Food and Drug Administration, Center for Drug Evaluation and Research (CDER), Center for Biologics Evaluation Research (CBER), 1998.
17 Symchowicz S, Winston L, Black J, Smith M, Calesnick B, Tabachnick II: Diazoxide blood levels in man. J Pharm Sci 1967;56:912-914.

18 Rowland M, Tozer TN: Constant-rate input; in: Clinical Pharmacokinetics and Pharmacodynamics, ed 4. Philadelphia, Lippincott Williams \& Wilkins, 2010, pp 259-291.

19 Vree TB, Lenselink B: Rapid determination of diazoxide in plasma and urine of man by means of high-performance liquid chromatography. J Chromatogr 1979;164:228-234.

20 Ogilvie RI: Diazoxide disposition and effect on vascular resistance and compliance in dogs. Hypertension 1981;3:225-232.

21 Kwadijk S, Torano JS: High-performance liquid chromatographic method with ultraviolet detection for the determination of dapsone and its hydroxylated metabolite in human plasma. Biomed Chromatogr 2002;16:203208.

22 Ette EI: Stability and performance of a population pharmacokinetic model. J Clin Pharmacol 1997;37:486-495.

23 Efron B, Tibshirani R: Bootstrap methods for standard errors, confidence intervals, and other measures of statistical accuracy. Stat Sci 1986;1:54-77.

24 Kawakita R, Sugimine H, Nagai S, et al: Clinical characteristics of congenital hyperinsulinemic hypoglycemia in infant: a nationwide epidemiological survey in Japan. J Jpn Pediatr Soc 2011;115:563-539. 